\title{
Increasing the Discharge Rate Capability of Lithium-Ion Cells with Laser-Structured Graphite Anodes: Modeling and Simulation
}

\author{
Jan B. Habedank, $\oplus^{1,=}$ Ludwig Kraft, $\oplus^{2,=, *, z}$ Alexander Rheinfeld, $\oplus^{2,=, *}$ \\ Christina Krezdorn, ${ }^{1}$ Andreas Jossen, ${ }^{2}$ and Michael F. Zaeh ${ }^{1}$ \\ ${ }^{1}$ Institute for Machine Tools and Industrial Management, Technical University of Munich (TUM), Munich, Germany \\ ${ }^{2}$ Institute for Electrical Energy Storage Technology, Technical University of Munich (TUM), Munich, Germany
}

\begin{abstract}
A physical-chemical model is suggested, which is able to describe the enhanced discharge rate capability of lithium-ion cells by using laser-structured graphite anodes. Recently published test data of coin cells comprising unstructured and structured graphite anodes with $\mathrm{LiNi}_{1 / 3} \mathrm{Co}_{1 / 3} \mathrm{Mn}_{1 / 3} \mathrm{O}_{2}$ cathodes is used for the presented purpose of modeling, simulation and validation. To minimize computational demand, a homogenized three-dimensional model of a representative hole structure is developed, accounting for charge and mass transport throughout the cell layers and one-dimensional diffusion within radial-symmetric particles. First, a standard pseudo-two-dimensional model is calibrated against rate capability test data of coin cells with unstructured anodes. The calibrated parameter set is transferred to the three-dimensional model in order to simulate the transient voltage response and the discharged capacity depending on the applied C-rate. The simulation data shows excellent agreement with experimental data for both cell types. Three stages of rate capability enhancement are identified showing an improved relative capacity retention of $11-24 \%$ at 3C. Experimental and simulation data reveal a restricted C-rate window, which can be positively affected by the structuring process, whereas both shape and pattern of the structuring process can be further optimized with the model.

(C) The Author(s) 2018. Published by ECS. This is an open access article distributed under the terms of the Creative Commons Attribution 4.0 License (CC BY, http://creativecommons.org/licenses/by/4.0/), which permits unrestricted reuse of the work in any medium, provided the original work is properly cited. [DOI: 10.1149/2.1181807jes]

(cc) BY
\end{abstract}

Manuscript submitted March 26, 2018; revised manuscript received May 4, 2018. Published May 23, 2018.

Lithium-ion batteries (LIBs) are the predominant energy storage solution for consumer electronics, electric vehicles and stationary energy storage devices. However, especially LIBs with high energy densities struggle to deliver sufficient energy at high discharge rates. ${ }^{1}$ This rate limitation is caused by internal cell resistances of diverse origins, which has recently been reported to be dominated by the ionic resistance in the liquid electrolyte for common LIB electrode morphologies and operation strategies. ${ }^{2,3}$ The electrodes of LIBs typically consist of active material particles mixed with binders and conductive agents and are coated onto metallic current collector foils. The pores of the electrodes and the electronically insulating separator are filled with the electrolyte solution, enabling ion transport between the electrodes. In most automotive LIBs, lithium nickel cobalt manganese oxide $\mathrm{Li}\left(\mathrm{Ni}_{x} \mathrm{Co}_{y} \mathrm{Mn}_{\mathrm{z}}\right) \mathrm{O}_{2}(\mathrm{NMC})$ is employed as the cathode active material due to its high specific capacity and voltage level vs. $\mathrm{Li} / \mathrm{Li}^{+}$. For nearly all commercially available cells, graphite is used as the anode active material. Natural graphite particles have a flake-like shape, which makes them align parallel to the current collector foil during the coating and the subsequent calendering process. This particle orientation implies a strong tortuosity anisotropy within the graphite anodes, creating particularly long diffusion pathways for Li-ion transport through the electrode. ${ }^{4}$ This results in large Li-ion concentration gradients within the electrode at high charge and discharge rates, causing concentration overpotentials and, consequently, a premature approach of the voltage limits resulting in an insufficient usage of the available capacity. ${ }^{3}$

Previously, it has been demonstrated that structured electrodes can have a positive impact on the cell's performance at higher current rates. ${ }^{5}$ Multiple fabrication processes have been introduced, such as co-extrusion of the active material ${ }^{6}$ and combinations of extrusion and sintering processes. ${ }^{7}$ Many of the battery concepts involve a three-dimensional (3D) cell setup, in which the electrodes interlock on a micro or nano scale, creating a large reaction surface area and excellent charge transfer characteristics. ${ }^{8}$ As laser-based manufacturing processes have been gaining importance in the processing industry over the past decades, particular attention has been given to laser-structuring of state-of-the-art electrodes. This concept involves high-precision ablation of a small fraction of the active material from the initial coating, generating additional diffusion pathways, which

$=$ These authors contributed equally to this work.

*Electrochemical Society Student Member.

${ }^{\mathrm{z}}$ E-mail: ludwig.kraft@tum.de are solely filled with electrolyte. Significant improvements in rate capability were observed for laser-structured cathodes, e.g. consisting of lithium manganese oxide $\mathrm{LiMn}_{2} \mathrm{O}_{4},{ }^{9}$ as well as for graphite anodes. ${ }^{10}$

A few simulation-based approaches have been published in the past, explaining the improved rate capability for structured cathodes $^{6,11}$ and anodes ${ }^{12}$ due to the reduced overall tortuosity of the electrodes. Based on the structuring process, a more homogeneous active material utilization is achieved and overpotentials are reduced during operation. To the knowledge of the authors, no experimentally validated physical-chemical model of LIBs with structured graphite anodes has been presented so far. Such a model, however, is needed to optimize the geometry of the superimposed structure while taking manufacturing constraints into account. In the work presented here, a homogenized 3D model of an NMC/graphite cell with laser induced microstructures within the anode is introduced taking onedimensional (1D) diffusion within the solid particles into account. The adapted 3D+1D electrochemical model is based on Newman's pseudo two-dimensional (p2D) model of a $\mathrm{LIB}^{13}$ accounting for both theories of porous electrodes and concentrated solutions. ${ }^{14}$ The presented model is implemented and solved with the aid of a commercially available finite element method (FEM) tool. Geometrical features of the electrodes are matched to previously measured data. ${ }^{10}$ Most relevant material parameters, such as the open circuit potentials of the used materials, were determined experimentally. The model is utilized to not only predict the transient voltage curves for discharge rates from $\mathrm{C} / 5$ to $10 \mathrm{C}$ and the derived capacity at the end of discharge, but also to determine Li-ion concentration gradients throughout the cell representing the cause of overpotentials during operation. The simulation results show excellent accordance with experimental data collected during the considered rate capability tests. Based on these results, the presented model can be used for optimizing a superimposed electrode structure, allowing for further improvements in terms of rate capability of LIBs.

\section{Experimental}

In this section, the experimental procedures for electrode fabrication, laser-structuring of the anodes as well as cell assembly and testing are described.

Electrode fabrication.-The components for the electrode inks were mixed with N-methyl-2-pyrrolidone (NMP, Sigma-Aldrich, USA) in a planetary vacuum mixer (Thinky Mixer ARV-310, Thinky, USA) for $10 \mathrm{~min}$ at ambient pressure and temperature. The graphite 


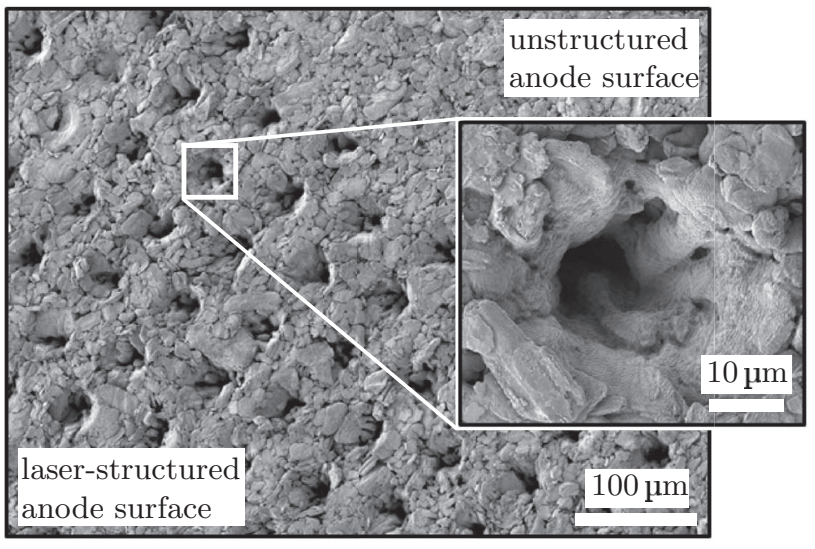

Figure 1. SEM image of a laser-structured anode with structured and unstructured parts.

ink contained $95 \mathrm{wt} \%$ graphite (SGL Carbon, Germany) and $5 \mathrm{wt} \%$ polyvinylidene fluoride (PVDF, Kynar, Arkema, France). The NMC ink was made of $96 \mathrm{wt} \% \mathrm{LiNi}_{1 / 3} \mathrm{Co}_{1 / 3} \mathrm{Mn}_{1 / 3} \mathrm{O}_{2}$ (BASF, Germany), $2 \mathrm{wt} \%$ PVDF and $2 \mathrm{wt} \%$ conductive carbon (C65, Timcal, Switzerland). Slot die coating was performed in an industrial roll-to-roll coating machine (Coatema, Germany) equipped with an infrared dryer at a coating speed of $1 \mathrm{~m} \mathrm{~min}^{-1}$. Subsequently, the coatings were calendered to a final porosity of approximately $35 \%$. After calendering, the average coating thickness was $64 \mu \mathrm{m}$ for both anode and cathode.

Laser-structuring of anodes.-For laser-structuring, a femtosecond laser (Spirit One 1040-8, Spectra-Physics, USA), operating at an infrared wavelength of $\lambda=1040 \mathrm{~nm}$ with a pulse duration $\tau_{\mathrm{p}}$ of $400 \mathrm{fs}$ was used. Only the anodes were structured, the NMC cathodes remained pristine as a larger effect on the overall tortuosity can be achieved in comparison. The beam diameter $d_{0}$ in the focal plane (on the electrode surface) was $17.2 \mu \mathrm{m}$ and the peak fluence $\Phi_{0}$ was $33.6 \mathrm{~J} \mathrm{~cm}^{-2}$. The repetition rate $f_{\text {rep }}$ used for ablation was $1 \mathrm{kHz}$ and a pulse number $n=100$ was applied to achieve an average structure depth $d_{\mathrm{s}}$ of approximately $52 \mu \mathrm{m}$ and an average structure diameter of approximately $20 \mu \mathrm{m}$ at the electrode's surface, measured with a confocal microscope. Toward deeper parts of the electrode (close to the current collector), the structures narrowed. The structures were spatially distributed in a hexagonal shape with a lateral length of $70 \mu \mathrm{m}$, resulting in approximately 20400 structures per $\mathrm{cm}^{2}$. The ablated fraction of the coating materials for the chosen process parameters was around $5 \mathrm{wt} \%$ of the composite electrode material, determined by weighing electrodes before and after structuring. For more details on the experimental setup, the reader is referred to Habedank et al. ${ }^{10}$ An image of the resulting structure distribution and geometry gained by means of scanning electron microscopy (SEM) is presented in Fig. 1. It becomes apparent, that the laser-induced structures are not uniformly shaped as the electrode consists of particles of different sizes and shapes. The local electrode conditions thus play a decisive role in the resulting characteristics of the structure.

Half cell assembly and open circuit potentials.-The open circuit potential curves of the utilized unstructured graphite and NMC electrodes were measured in 2032 type coin cells vs. a lithium metal electrode. The half cells were assembled in an argon filled glove box (M. Braun Inertgas-Systeme, Germany) with $\mathrm{H}_{2} \mathrm{O}<0.1 \mathrm{ppm}$ and $\mathrm{O}_{2}<0.1 \mathrm{ppm}$. Each cell was filled with $150 \mu \mathrm{l}$ of electrolyte (LP57, BASF, Germany), containing ethylene carbonate (EC) and ethyl-methyl-carbonate (EMC) in a ratio of 3:7 (by weight) with $1 \mathrm{M}$ lithium-hexaflourophosphate $\left(\mathrm{LiPF}_{6}\right)$. As a separator, a glass microfiber sheet (Type 691, VWR, USA) was employed. In its uncompressed state, the separator has a thickness of $260 \mu \mathrm{m}$. Due to the compression during cell assembly, the separator thickness was estimated to be $200 \mu \mathrm{m} .{ }^{15}$ For the measurement of the quasi open circuit potential as a function of the degree of lithiation, the cells were charged and discharged three times at rates of C/50 in a dry room at a controlled temperature of $20^{\circ} \mathrm{C}$ between $4.3 \mathrm{~V}$ and $2.9 \mathrm{~V}$ (NMC) and between $1.6 \mathrm{~V}$ and $0.05 \mathrm{~V}$ (graphite). In order to derive representative open circuit potential curves from this procedure, an averaging between lithiation (NMC) and delithiation (graphite) of the considered working electrode was carried out for all three C/50 cycles. The averaged open circuit potential curves that were used for modeling and simulation are shown in Fig. A1 in the Appendix. The individual cell capacities for specifying the applied C/50 current were calculated by determining the coating mass assuming mass specific capacities of $150 \mathrm{mAh} \mathrm{g}^{-1}$ for NMC and $360 \mathrm{mAh} \mathrm{g}^{-1}$ for graphite.

Full cell fabrication.-Three 2032 type coin cells with unstructured anodes and three coin cells with laser-structured anodes were assembled analogously to the half cell assembly described in the previous section. As common practice for $\mathrm{Li}$-ion cells, the areal capacities of the graphite anodes were slightly overdimensioned compared to the NMC cathodes in order to account for irreversible losses during formation and to avoid anode potentials below $0 \mathrm{~V}$, which would result in an undesired Li-plating reaction during charge. In the case presented here, an overdimensioning factor of approximately 1.2 of the pristine anode was chosen so that Li-plating could be avoided at all times during cycling. As only $5 \mathrm{wt} \%$ of the coating was removed during the laser-structuring process, this overdimensioning was considered sufficient so that Li-plating during charging could also be avoided in this case. As the mass loading of the pristine graphite anodes was kept constant, the structuring process inevitably resulted in a change in the capacity balancing of the electrodes. This effect needs to be taken into account especially during modeling and simulation and will be further discussed in the modeling section. As the electrolyte, LP572 (BASF, Germany) was used, which consists of EC and EMC in a gravimetric mixing ratio of 3:7 with $1 \mathrm{MLiPF}_{6}$ conductive salt and $2 \mathrm{wt} \%$ vinylene carbonate (VC). As the full cell test data has already been published elsewhere, ${ }^{10}$ no further details on the cell fabrication procedure are discussed here. The focus of the work presented here lies on model validation by means of this experimental test data, which is why only essential information is given. Material and fabrication parameters relevant for modeling and simulation purposes are listed in the Appendix of this paper.

Formation procedure.-All cells went through a formation procedure of three charge and discharge cycles at a C-rate of $\mathrm{C} / 10$ in order to sufficiently form the solid electrolyte interphase (SEI) on the surface of the graphite particles before the subsequent rate capability test was carried out. Charging was conducted using a constant current/constant voltage (CCCV) operation with a cutoff current of $\mathrm{C} / 20$ and discharging was performed in a constant current $(\mathrm{CC})$ procedure within a voltage window of $4.2 \mathrm{~V}$ to $3.0 \mathrm{~V}$ at a constant temperature of $20^{\circ} \mathrm{C}$.

Rate capability test.-After formation, the cells underwent a rate capability test at a controlled temperature of $20^{\circ} \mathrm{C}$ whereas the applied current was derived from the capacity of the cell after the last formation cycle at $\mathrm{C} / 10$. The area-specific values for the adapted $\mathrm{C} / 10$ discharge current are shown in Table I for each individual cell considered in this study. As can be seen from this table, all cells investigated in this work showed comparable areal capacities with only slight deviations between the samples. This was considered to be of major importance in order to allow for a straightforward comparison in absolute capacity retention. Higher C-rates are a multiple of the corresponding $\mathrm{C} / 10$ discharge current. Charging was carried out following a CCCV procedure and discharging was performed in a $\mathrm{CC}$ procedure within a voltage window between $4.2 \mathrm{~V}$ and $3.0 \mathrm{~V}$ from $\mathrm{C} / 10$ to $10 \mathrm{C}$. The constant voltage $(\mathrm{CV})$ phase during charge was terminated when a charging current smaller than $\mathrm{C} / 20$ was reached. Charging currents were $\mathrm{C} / 10$ and $\mathrm{C} / 5$ for the corresponding discharge cycles of $\mathrm{C} / 10$ and $\mathrm{C} / 5$, respectively. After that, a charging current of $\mathrm{C} / 2$ was applied. 
Table I. C/10 discharge currents matched to cell capacities of coin cells comprising unstructured and structured anodes.

\begin{tabular}{|c|c|c|}
\hline & & $\begin{array}{l}\text { Discharge current } \\
\text { in } \mathrm{mA} \mathrm{cm}^{-2}\end{array}$ \\
\hline \multirow{4}{*}{$\begin{array}{l}\text { Unstructured } \\
\text { anode }\end{array}$} & Cell 1 & 0.2399 \\
\hline & Cell 2 & 0.2535 \\
\hline & Cell 3 & 0.2597 \\
\hline & Average & 0.2510 \\
\hline \multirow{4}{*}{$\begin{array}{l}\text { Structured } \\
\text { anode }\end{array}$} & Cell 4 & 0.2597 \\
\hline & Cell 5 & 0.2445 \\
\hline & Cell 6 & 0.2501 \\
\hline & Average & 0.2514 \\
\hline
\end{tabular}

The resulting discharge rate capability is shown in Fig. 2. As can be seen from this figure, all investigated cells show quite comparable behavior. The cells containing structured anodes show an even more reproducible behavior compared to the cells with unstructured anodes. As can be clearly seen from the experiments in Fig. 2, the structuring process results in an overall improvement of the cell's absolute capacity retention, which becomes dominant beyond $2.5 \mathrm{~mA} \mathrm{~cm}^{-2}$ or $1 \mathrm{C}$ and fades again before $25 \mathrm{~mA} \mathrm{~cm}^{-2}$ or $10 \mathrm{C}$. This effect will be further evaluated in the following sections.

Cyclic aging test.-Subsequent to the rate capability tests, the six coin cells comprising unstructured and structured anodes underwent a cycling test of 1000 cycles. The cells were charged with a CCCV procedure following a charging current of $1 \mathrm{C}$ until the cutoff voltage of $4.2 \mathrm{~V}$ and a cutoff current of $\mathrm{C} / 5$ in the $\mathrm{CV}$ phase. The discharge was carried out with a $\mathrm{CC}$ phase at a $1 \mathrm{C}$ discharge current until a cutoff voltage of $3.0 \mathrm{~V}$. Similar to the rate capability tests, the ambient temperature was set to $20^{\circ} \mathrm{C}$. The capacity retention of the first CC discharge cycle was used as a reference. The capacity fade of each cell as a result of cyclic aging is displayed in Fig. 3.

\section{Modeling}

In accordance with the homogenized p2D modeling approach for porous microstructures developed by Newman, Doyle and Fuller, ${ }^{13,14,16}$ the model presented here consists of an anode, a separator, and a cathode domain in which both charge and mass transport are accounted for. The governing equations rely on porous electrode and concentrated solution theories and are listed in the appendix for the reader's convenience. Relevant model parameters representing the investigated coin cells are summarized in Table AI in the appendix. The Newman model originally considers a $1 \mathrm{D}$ representation through the layers of the electrochemical cell which is coupled to a second di-

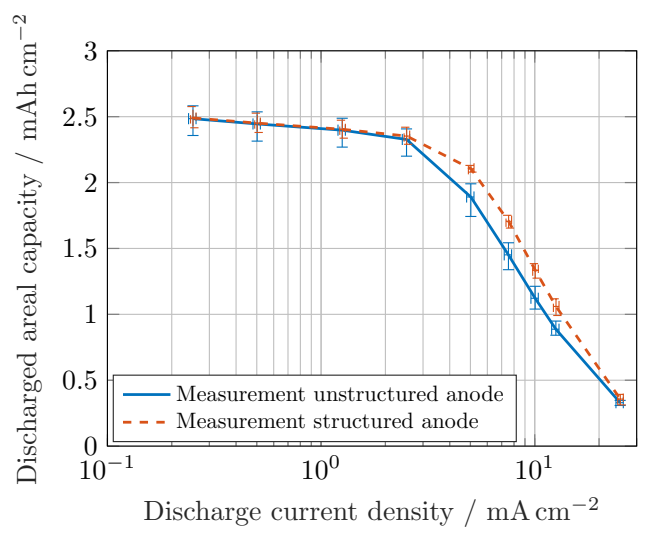

Figure 2. Measured area-specific discharge capacity as a function of applied current density of coin cells comprising unstructured and structured anodes.

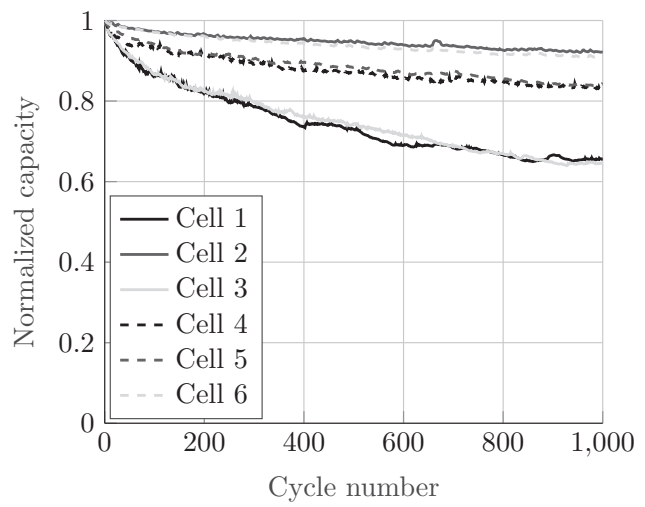

Figure 3. Normalized capacity retention during cycling of cells comprising unstructured anodes (Cell 1, Cell 2 and Cell 3) and structured anodes (Cell 4, Cell 5 and Cell 6).

mension representing radial-symmetric active material particles (i.e. $1 \mathrm{D}+1 \mathrm{D}$, hence $\mathrm{p} 2 \mathrm{D})$. This approach has proven to be valid if the cell shows a homogeneous behavior in the second and third in-plane dimension which allows to neglect gradients in these dimensions as the cell behavior is dominated by through-plane charge and mass transport. ${ }^{17,18}$ Only if these gradients cannot be ruled out due to e.g. the non-ideal spatial configuration of the current collectors and the positioning of the corresponding tabs, further means of model development need to be considered. ${ }^{19,20}$

In the case presented here, 1D and 2D models cannot be used to appropriately describe the hole structure created by the laser ablation process as gradients are expected to occur due to the spatial distribution of the superimposed structure. Furthermore, as already stated in the laser-structuring section, the hole structure is not uniform throughout the entire electrode but is highly dependent on the size and shape of the particles which are affected by the ablation process resulting in a rather coarse hole structure when visually comparing the holes one by one. In order to account for a representative hole structure on the one hand and in order to limit computational effort on the other hand, a homogenized 3D representation of the electrode layers is considered which is coupled to the aforementioned additional radial dimension representing the active material particles. This simplification follows the same line of thought initially suggested by the Newman group in order to efficiently describe porous insertion materials. If the electrode is large enough in terms of its planar dimensioning, every location along an electrode's normal vector can be represented by one particle that will be in contact with the surrounding electrolyte leading to the $\mathrm{p} 2 \mathrm{D}$ approach, which is widely accepted and applied. The same principle accounts for a representative hole structure describing the general behavior of the structured electrode. Following this idea, there will be a particle at every location within the representative 3D structure which will be in contact with the surrounding electrolyte at this very location. Furthermore, a generalized or simplified hole structure representing the 20400 holes per $\mathrm{cm}^{2}$ can be introduced. The specified differential equations have to be consequently solved in all three spatial dimensions of the homogenized 3D cell setup which implies:

$$
\nabla:=\left(\frac{\partial}{\partial x}, \frac{\partial}{\partial y}, \frac{\partial}{\partial z}\right)
$$

Due to the increased spatial discretization effort, 3D models tend to have larger degrees of freedom (DOF), which inevitably causes a higher computational demand and, hence, longer computing times. To minimize the computational effort for solving the set of partial differential equations, the modeled electrode section takes most advantage of symmetry planes representing the structuring pattern. The definition of the modeled geometry is shown in Fig. 4. The laser ablation process creates holes in a hexagonal pattern as can be seen from Fig. 1. The $x$-direction of the modeled section represents the direction perpendicular to the layers of the cell following the same notation 
(a)

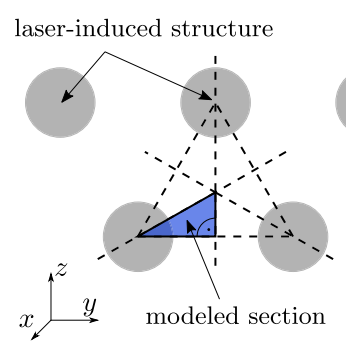

(b)

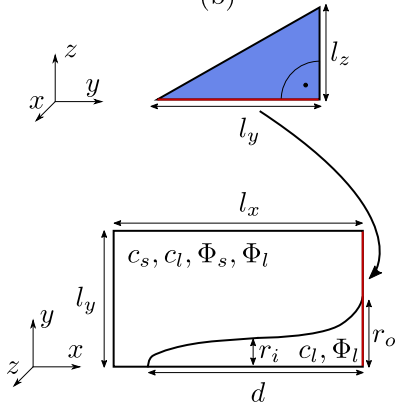

(c)

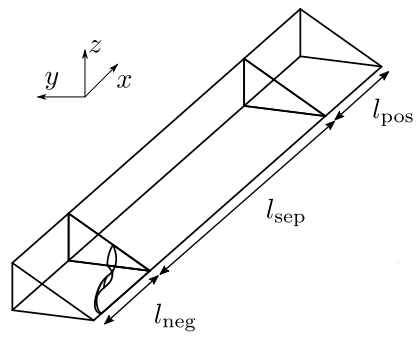

Figure 4. Definition of the modeled geometry using symmetry characteristics of the laser-structured anode. Representative anode surface (a), anode cross section (the state variables solved per domain are the solid and liquid phase Li-ion concentration $c_{\mathrm{S}}$ and $c_{\mathrm{l}}$ and the solid and liquid phase potential $\Phi_{\mathrm{S}}$ and $\Phi_{\mathrm{l}}$, respectively) (b) and final 3D geometry implemented in the FEM tool (c).

as the original Newman model. As the holes are homogeneously distributed across the cell, a triangular section of the structured anode is sufficient to describe the entire cell behavior, see Fig. 4a. In this case, a $30^{\circ}$ sector of the hexagonal structuring pattern is specified. The cross section of the anode is shown in Fig. $4 \mathrm{~b}$ with $l_{x}, l_{y}$ and $l_{z}$ representing the length in $x$-, $y$ - and $z$-direction, respectively. In this case, $l_{x}$ is equal to the thickness of the negative electrode $l_{\text {neg }}$. The distance between the centers of two adjacent holes accounts for $2 l_{y}$. The inner radius of the hole is described by $r_{\mathrm{i}}$, the outer radius by $r_{\mathrm{o}}$ and the depth by $d$. As the structures are not perfectly cylindrical, the shape was built by using a cubic Bézier curve

$$
B(t)=(1-t)^{3} P_{0}+3(1-t)^{2} t P_{1}+3(1-t) t^{2} P_{2}+t^{3} P_{3}
$$

The Bézier curve runs in the interval $0 \leq t \leq 1$. It starts at $P_{0}$ for $t=0$ and terminates in the last control point for $t=1$. Each control point $P_{n}$ is defined by its $x_{n}$ and $y_{n}$ component, the shape of the curve was controlled by the weighting coefficients $w_{1}$ and $w_{2}$. The control points are provided in Table II.

$$
P_{n}=\left(\begin{array}{l}
x_{n} \\
y_{n}
\end{array}\right), n=0,1,2,3
$$

All remaining parameters are listed in the Appendix in Table AI. The resulting idealized $3 \mathrm{D}$ geometry is displayed in Fig. 4c. The volume fraction of the modeled hole is $5.1 \%$ of the initial anode volume, which is in good agreement with the results of the laserstructuring process. To account for a reduced anode volume, the initial degree of lithiation of the unstructured anode was increased from $0.78 \cdot c_{\mathrm{s}, \max \text {, neg }}$ (see Table AI) to $0.82 \cdot c_{\mathrm{s}, \max \text {, neg }}$ for the structured anode which represents this relative decrease. The thicknesses of the separator $l_{\text {sep }}$ and the positive electrode $l_{\text {pos }}$ are added to the geometry in $x$-direction.

The presented model of the Li-ion cell was implemented in the FEM-based software platform COMSOL Multiphysics 5.3. In order to depict the geometrical features of the hole, a high spatial discretization around the hole boundaries was chosen resulting in approximately 30000 DOF which need to be solved during computation. For comparison, a 3D model of an unstructured cell with a similar spatial discretization along the $x$-axis results in approximately 9000 DOF. For describing the unstructured cell, a classic p2D model with around 2000 DOF was chosen in order to save computing time.

Table II. $x$ and $y$ components of the four control points.

\begin{tabular}{ccc} 
& $x_{n}$ & $y_{n}$ \\
\hline$P_{0}$ & $l_{\text {neg }}-d$ & 0 \\
$P_{1}$ & $l_{\text {neg }}-d$ & $r_{\mathrm{i}} w_{1}$ \\
$P_{2}$ & $l_{\text {neg }}$ & $r_{\mathrm{i}} w_{2}$ \\
$P_{3}$ & $l_{\text {neg }}$ & $r_{\mathrm{o}}$
\end{tabular}

In order to describe charge and mass transport in the porous microstructures of a Li-ion cell, a correction of the electrolyte's transport properties is necessary. An often used correction factor is the Bruggeman exponent which was empirically determined for porous structures formed of spherical particles. Recent research findings showed that the Bruggeman correction often underestimates the limitation of the transport properties especially in graphite electrodes formed of platelet-like particles. ${ }^{4,21-24}$ In order to evaluate effective transport parameters, the tortuosity $\tau$ of the porous electrode structure needs to be known, which can be defined as the ratio of the direct path length to the effective path length of ion transport

$$
\begin{gathered}
D_{\mathrm{l}, \mathrm{eff}}=D_{1} \frac{\varepsilon_{1}}{\tau}=\frac{D_{1}}{N_{\mathrm{M}}} \\
\kappa_{\mathrm{eff}}=\kappa \frac{\varepsilon_{1}}{\tau}=\frac{\kappa}{N_{\mathrm{M}}}
\end{gathered}
$$

with $D_{1}$ representing the diffusion coefficient in the liquid phase (i.e. the electrolyte), $\kappa$ its conductivity and $\varepsilon_{1}$ the volume fraction of the electrolyte, also known as the porosity of the porous structure. The ratio of the tortuosity to the volume fraction is also known as the MacMullin number $N_{\mathrm{M}} \cdot{ }^{24-26}$ Ebner et al. further demonstrated that the electrode's tortuosity for spherical particles (e.g. NMC) shows an isotropic behavior, but for cylindrical (e.g. lithium cobalt oxide $\mathrm{LiCoO}_{2}(\mathrm{LCO})$ ) and platelet-shaped particles (e.g. graphite), an anisotropy of tortuosity can be observed that cannot be neglected when considering charge and mass transport in all spatial dimensions of an electrode. ${ }^{4}$ Especially the through-plane tortuosity of graphite $\tau_{x}$ is significantly higher than the in-plane tortuosity (with $\tau_{y}=\tau_{z}$ ). In order to account for this effect, an anisotropic tortuosity was implemented in the graphite anode with $\tau_{x}=8$ and $\tau_{y}=\tau_{z}=2.5$. $^{4}$ The separator and the NMC cathode were considered to inhibit an isotropic tortuosity of $\tau_{x}=\tau_{y}=\tau_{z}=1.2$ and $\tau_{x}=\tau_{y}=\tau_{z}=1.7$, respectively (see Table AI).

\section{Results and Discussion}

In this section, the data gained from the rate capability tests carried out for this work is presented and then discussed with the aid of simulation studies derived from the developed modeling approach. The results of the cyclic aging experiments carried out after the rate capability tests are discussed at the end of the section.

Effects of structuring on rate capability.-All rate capability tests were carried out as described in the experimental section at $\mathrm{C} / 10, \mathrm{C} / 5$, $\mathrm{C} / 2,1 \mathrm{C}, 2 \mathrm{C}, 3 \mathrm{C}, 4 \mathrm{C}, 5 \mathrm{C}$ and $10 \mathrm{C}$ at an ambient temperature of $20^{\circ} \mathrm{C}$. As the coulombic efficiency of the $\mathrm{C} / 10$ cycles after the formation procedure was only $99.1 \%$ on average, this data is not considered in the further process of this work. The authors believe that the process of formation was not completely finished at this stage, which might falsify the observed trends if taken into consideration here. From the 
(a)

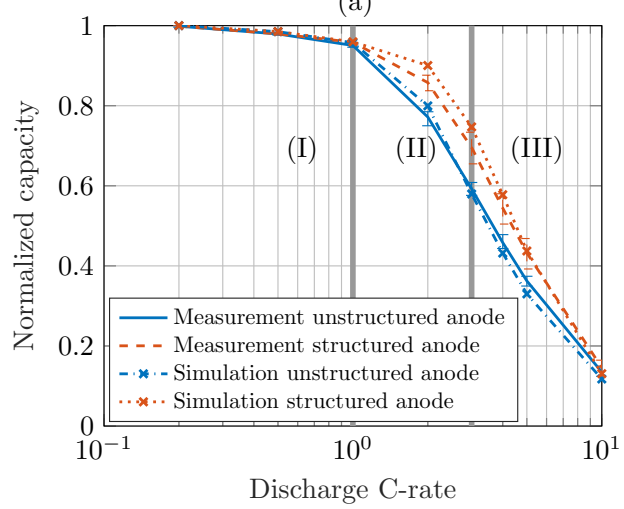

(b)

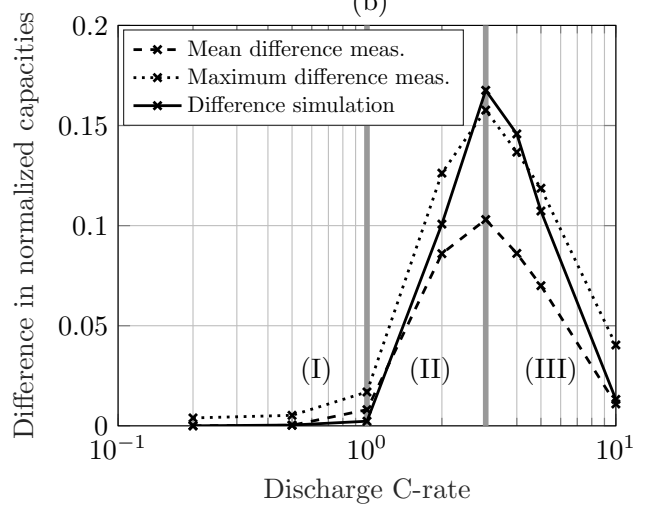

Figure 5. Comparison of measured and simulated C/5-normalized discharge rate capability of coin cells comprising unstructured and structured anodes (a) and observed difference in normalized discharge rate capability (b) within the three stages (I), (II) and (III).

$\mathrm{C} / 5$ cycles onwards, all cycles showed efficiencies above this value rising toward $99.7 \%$. Therefore, all further observations were focused on C-rates larger than $\mathrm{C} / 10$.

In Fig. 2, the mean area-specific discharged capacity is shown as a function of applied current density. As indicated by the error bars, a variation in both directions occurs, whereas the variation in applied current follows the notation presented in Table I, which is based on the derived capacity at the end of the carried out formation cycles. The cathode samples used for building the coin cells were chosen in such way, that the loading of the capacity limiting electrode, i.e. the cathode, was very similar for both unstructured and structured cells (see experimental section). This approach resulted in a highly reproducible area-specific capacity of approximately $2.5 \mathrm{mAh} \mathrm{cm}^{-2}$ at low current densities for all cells considered within this study, which guarantees a most straightforward comparison of the results gained from the rate capability tests. For the reader's convenience, besides area-specific values (see Fig. 2), also the capacity retention normalized to the $\mathrm{C} / 5$ discharge rate (see Fig. 5a) and the difference in normalized capacity retention (see Fig. 5b) is shown in this work. When looking into the difference in normalized capacity retention, the impact of electrode structuring can be categorized in three different stages depending on the applied C-rate and increase in derived capacity. The area-specific energy density is not shown here, as the voltage level only merely varies between coin cells with structured and unstructured anodes. Therefore, the area-specific capacity and area-specific energy density as a function of applied C-rate show very similar characteristics in this work. As the volume of the anode does not change with the structuring process, the volumetric energy density of the cell directly follows this trend. Based on the lower density of the electrolyte compared to the composite anode, the overall weight of the electrolyte soaked
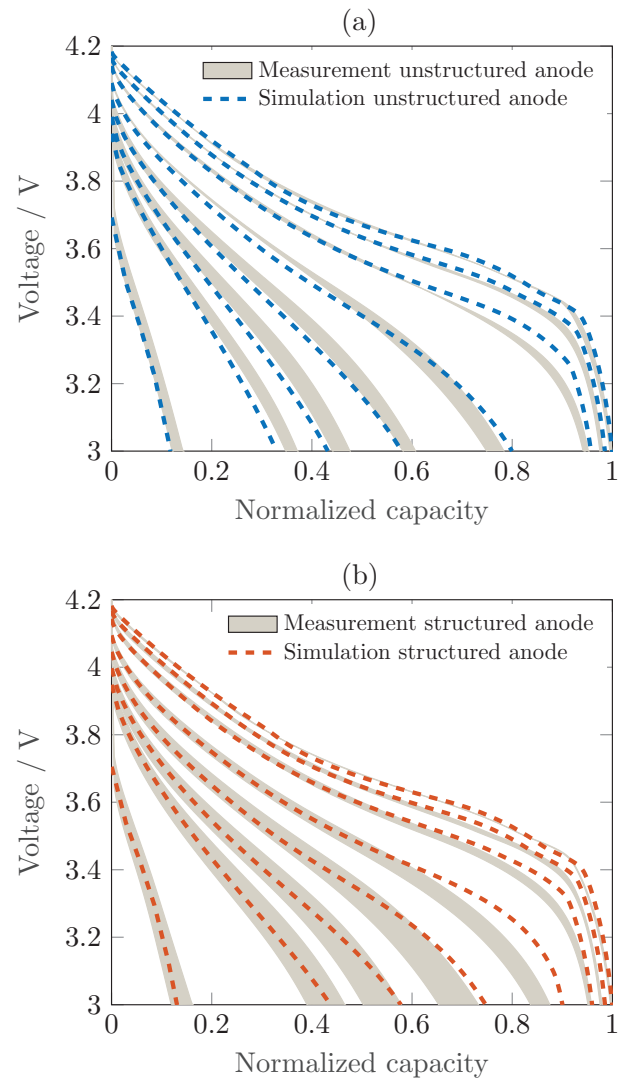

Figure 6. Comparison of measured and simulated discharge voltage curves as a function of $\mathrm{C} / 5$-normalized capacity for coin cells comprising unstructured (a) and structured anodes (b) for C-rates of C/5, C/2, 1C, 2C, 3C, 4C, 5C, and 10C (from right to left).

anode is reduced by approximately $3 \%$. This will slightly improve the gravimetric energy density of the full cell. For all applied currents, the coin cells comprising structured anodes generally showed a larger discharged capacity compared to their unstructured counterpart, as can be seen in Fig. 2. In the case presented in this study, this effect suddenly becomes dominant at discharge current densities above $2.5 \mathrm{~mA} \mathrm{~cm}^{-2}$ or $1 \mathrm{C}$ reaching its peak impact around $7.5 \mathrm{~mA} \mathrm{~cm}^{-2}$ or $3 \mathrm{C}$ and steadily declines at current densities above this value as shown in Fig. 5b. As can also be seen from Figs. 2 and 5a, there is a rather gentle decrease of the discharged capacity with increasing current density up to $2.5 \mathrm{~mA} \mathrm{~cm}^{-2}$ or $1 \mathrm{C}$, which then becomes more pronounced up to $7.5 \mathrm{~mA} \mathrm{~cm}^{-2}$ or $3 \mathrm{C}$ and then finally decreases again in its steepness. In order to understand the interplay of mechanisms leading to this effect, the presented model was applied. For this purpose, a standard p2D Newman model was considered first, in order to match the parameter set to the results of the rate capability tests with cells comprising unstructured anodes. As shown in Figs. 5a and $6 \mathrm{a}$, the relative decline in capacity retention with rising C-rate at the end of the discharge as well as the transient characteristics of the voltage response during discharge can be depicted very well with the parameter set given in the Appendix.

This parameter set was then transferred to the $3 \mathrm{D}$ representation of the homogenized structured electrode model. With a simulated hole diameter of roughly $20 \mu \mathrm{m}, 80 \%$ of penetration depth and $70 \mu \mathrm{m}$ of distance between the centers of the holes, the rate capability tests performed on cells comprising structured anodes could also be depicted very well. Again, this accounts for both the absolute and the relative decline in discharged capacity with rising $\mathrm{C}$-rate at the end of the discharge procedure (see Fig. 5a) as well as the transient characteristics of the voltage response during discharge (see Fig. 6b). 


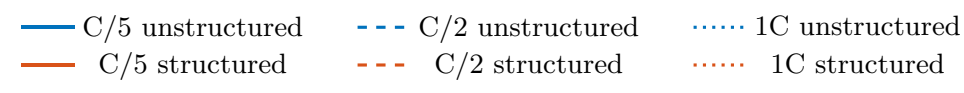

(a)

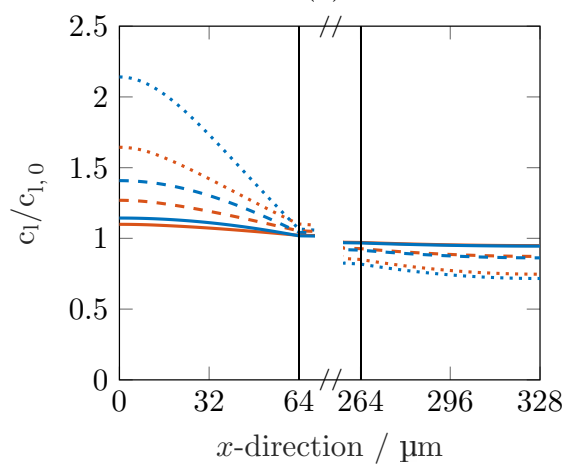

(b)

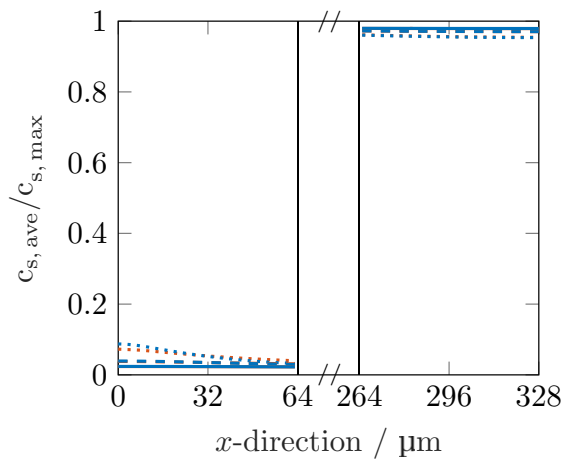

$\begin{array}{cc}-2 \mathrm{C} \text { unstructured } & ---3 \mathrm{C} \text { unstructured } \\ 2 \mathrm{C} \text { structured } & ---3 \mathrm{C} \text { structured }\end{array}$

(c)

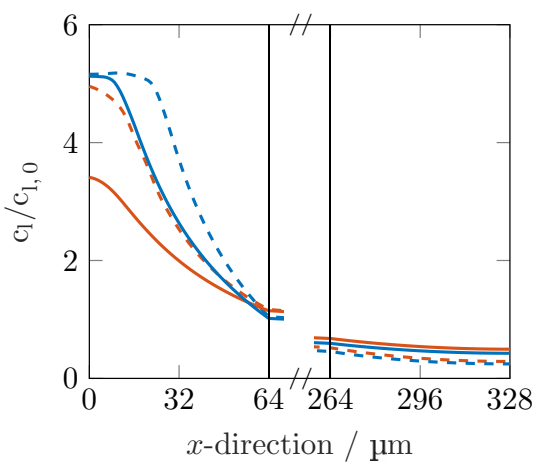

(d)

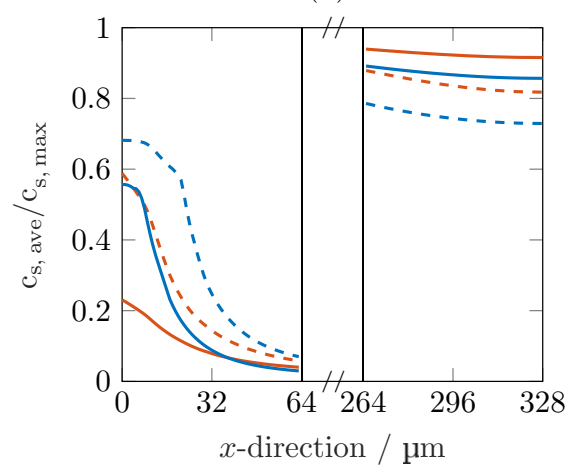

- 4C unstructured - - - 5C unstructured $\quad \cdots \cdots 10 \mathrm{C}$ unstructured

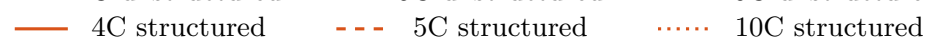

(e)

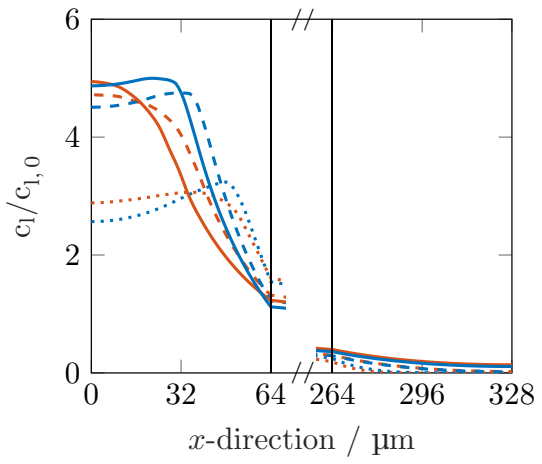

(f)

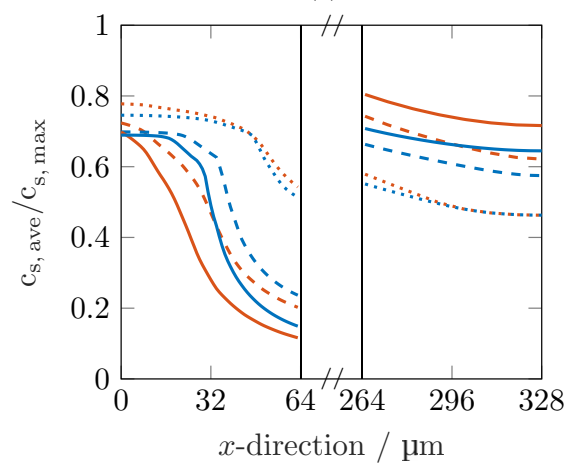

Figure 7. Li-ion concentration in both liquid (left) and solid phase (right) averaged along $y$-and $z$-direction at the end of the corresponding discharge step; solid phase concentration accounts for the mean concentration within the particle dimension.

Mechanisms of rate limitation.-When looking into Fig. 5a, the $\mathrm{C}$-rates of $\mathrm{C} / 5, \mathrm{C} / 2$ and $1 \mathrm{C}$ are almost not affected by the structuring process. Also, the similar trend of the decline in discharged capacity hints at a limiting effect which is not influenced by the structuring process and consequently charge and mass transport in the liquid phase. This assumption can be proven when looking into Figs. 7a and 7b. The spatial distribution in liquid phase concentration at the end of the discharge procedure is almost identical for both the unstruc- tured and structured cells with rising gradients between the anode and cathode for increasing C-rate. The same holds true for the spatial distribution in solid phase concentration. The utilization of the electrodes is constantly above $90 \%$ with almost no gradients along the thickness of the electrodes. At C-rates of $1 \mathrm{C}$ and below, this observation leads to the assumption that the capacity retention is mainly influenced by an increased potential drop based on ohmic losses and charge transfer kinetics with increasing C-rate. From $2 \mathrm{C}$ onwards, a 
more homogeneous liquid phase concentration can be observed for the cells with structured anodes compared to those with unstructured anodes with lower maximum values, which positively influences the transport properties of the electrolyte (see Fig. 7c). This results in a considerably homogenized solid phase concentration along the electrode with lower mean values on the anode side which leads to higher overall solid phase concentrations on the cathode side at the end of the discharge procedure (see Fig. 7d). At C-rates of $4 \mathrm{C}$ and above, the homogenizing influence of laser beam structuring on both the liquid and the solid phase concentration is considerably diminished as shown in Figs. 7e and 7f. At these C-rates, the limiting influence in the liquid phase on the cathode side becomes increasingly dominant, reaching almost a complete depletion of Li-ions, which results in large overpotentials related to charge transfer kinetics (see Fig. 7e). In addition, the liquid phase concentration within the anode domain rises above $4 \mathrm{moll}^{-1}$ which significantly reduces both its conductivity and diffusivity resulting in large ohmic and diffusion based overpotentials. The electrolyte conductivity is reduced to $35 \%$ and the diffusivity to $14 \%$ at $4 \mathrm{moll}^{-1}$ compared to the values at the initial liquid Li-ion concentration of $1 \mathrm{moll}^{-1}$. In order to improve the rate capability of the cell at these high discharge rates, further modifications need to be considered such as different electrolytes with enhanced transport properties at such high levels of Li-ion concentration or an additional structuring of the cathode to avoid a complete depletion of Li-ions.

These observations suggest a classification of the influence of laser beam structured anodes on the rate capability of the cells: At low C-rates, electrode morphology plays only a minor role in capacity retention making laser beam structuring obsolete in general, i.e. stage (I) between $0.1 \mathrm{C}$ and $1 \mathrm{C}$ in this case. At moderate C-rates, the effect of anode morphology and related effective transport properties becomes dominant, showing the largest benefit of laser beam structured anodes, i.e. stage (II) between $1 \mathrm{C}$ and $3 \mathrm{C}$ in this case. At high C-rates, not only the anode morphology is mainly influencing the occuring overpotentials, but also the electrolyte's inherent transport properties as well as the morphology of the separator and cathode are becoming increasingly important approaching a depletion of the electrolyte near the cathode current collector, i.e. stage (III) between $3 \mathrm{C}$ and $10 \mathrm{C}$ in this case. It is worth mentioning here, that the chosen glass fiber separator is not representative for commercial Li-ion cells, where separators are used which are about a magnitude thinner (i.e. approximately $10-30 \mu \mathrm{m})$. The glass fiber separator was used in this case due to ease of handling and comparability between half cell and full cell measurements. For the here presented results, this circumstance should only have a mere influence on the investigated rate capability as the overpotentials within the separator are dominated by the effective transport properties of the electrolyte, resembling an effective path-length of ion movement. The chosen glass fiber separator shows a MacMullin number of approximately 1.7 in its compressed state of $200 \mu \mathrm{m}$, which results in an effective path-length for the Li-ions of $340 \mu \mathrm{m}$. A standard polyolefin based separator with a thickness of $25 \mu \mathrm{m}$ and a porosity of $40 \%$ inhibits a MacMullin number between 10 to $15,{ }^{24}$ resembling an effective path-length of $250-375 \mu \mathrm{m}$, which is very comparable to the chosen glass fiber separator.

In order to not only evaluate the through-plane but also the inplane penetration depth of the structuring procedure, the 3D spatial distribution of $\mathrm{Li}$-ion concentration in the solid and liquid phase was studied at the end of a $3 \mathrm{C}$ discharge step. For this purpose, five cut planes were introduced along the thickness of the structured anode (compare Fig. 4c) at a constant distance of $16 \mu \mathrm{m}$ between them (see Figs. 8a and $8 b$ ). Looking into the spatial distribution of both the liquid and solid phase concentration, a fairly homogeneous coloring of the cut planes can be observed, whereby the coloring level is mainly dominated by the through-plane distribution in Li-ion concentration. This implies that the concentration gradients along the hole's axis are generally larger than the concentration gradients along the hole's radial direction.

Near the interface between the anode and the separator (i.e. planes $\mathrm{V}$ and IV), there is only little variation in Li-ion concentration throughout the cut planes in both the liquid and the solid phase. This tendency is confirmed when looking into the normalized liquid and solid phase concentration along the hypotenuse symmetry axis of the considered triangular electrode domain (see Figs. $8 \mathrm{c}$ and $8 \mathrm{~d}$ ). Furthermore, we observe an increasing gradient from the bulk material between the holes to the center of the hole with increasing distance to the separator along the depth of the holes (i.e. planes III and II). In case of the liquid phase concentration, the spatial distribution within the unstructured part of the electrode (i.e. plane I) becomes fairly homogeneous again, however, at significantly elevated levels of concentration. This jump becomes especially apparent when looking into the level of liquid phase Li-ion concentration within the hole (i.e. at $y=z=0$ within planes V, IV and III) compared to the unstructured part of the electrode (i.e. at $y=z=0$ within plane I). A similar trend in the solid phase concentration can be observed, whereas a considerable gradient in Li-ion concentration remains near the current collector in the range of a third to a half of the total through-plane concentration difference, which can be explained by the comparably slow diffusion-based equalization process within the solid phase compared to the liquid phase. ${ }^{17}$ These observations imply that the penetration depth of the structuring process not only varies for the liquid and solid phase concentration but is highly dependent on the size and the depth of the hole as well as the distance between the holes. These results suggest that the size, the depth and the shape of the hole itself as well as the structuring pattern can be optimized in order to obtain an improved rate capability within a certain operating window and price range.

Cyclic aging behavior.-From the overall cycling behavior displayed in Fig. 3, no distinct indication can be observed that coin cells comprising structured or unstructured graphite anodes show superior aging characteristics. What is more, the developing spread between the cells might be a result of the manual cell assembly process or partial deterioration during the rate capability tests with high C-rates. Nevertheless, all cells comprising structured anodes reveal a capacity retention above $83 \%$ after 1000 cycles, whereas two cells with unstructured anodes already showed a capacity fade toward $65 \%$. This leads to the conclusion that the laser-structuring process of the graphite anodes has no negative impact on the cyclic aging behavior of the coin cells. If coin cells comprising structured anodes even show an enhanced aging behavior needs to be evaluated by means of further measurements including more cells and cells that did not undergo a rate capability test before the carried out aging study.

\section{Conclusions}

Within this work, a combination of experimental and simulationbased evaluation of laser-beam structured graphite electrodes for enhancing the discharge rate capability of a NMC/graphite Li-ion cell was presented. As the experimental basis of this work, coin cells with a constant loading of approximately $2.5 \mathrm{mAh} \mathrm{cm}^{-2}$ were manufactured, whereas the NMC cathode was the capacity limiting electrode and the pristine graphite anode was oversized by approximately $20 \%$ in capacity so that the laser beam ablation of roughly $5 \mathrm{wt} \%$ did not result in an elevated risk of Li-plating during cycling. For simulation purposes, a representative homogenized microstructure model of the considered laser-beam-structured graphite electrode was developed and validated against rate capability tests, which were performed on both coin cells with unstructured and structured graphite electrodes..$^{10}$ In a first step, the underlying physical and chemical model parameters were adapted toward the unstructured coin cells with the aid of a standard p2D Newman-type model resulting in an excellent agreement between experimental and simulated rate capability tests. This parameter set was then transferred to the homogenized 3D+1D microstructure model, forming a representative triangular section of the structuring pattern making most use of symmetry planes in order to minimize computational effort. Due to the inevitably higher spatial discretization effort around the hole geometry, which was qualitatively approximated by a cubic Bézier curve toward SEM pictures, the computational demand 

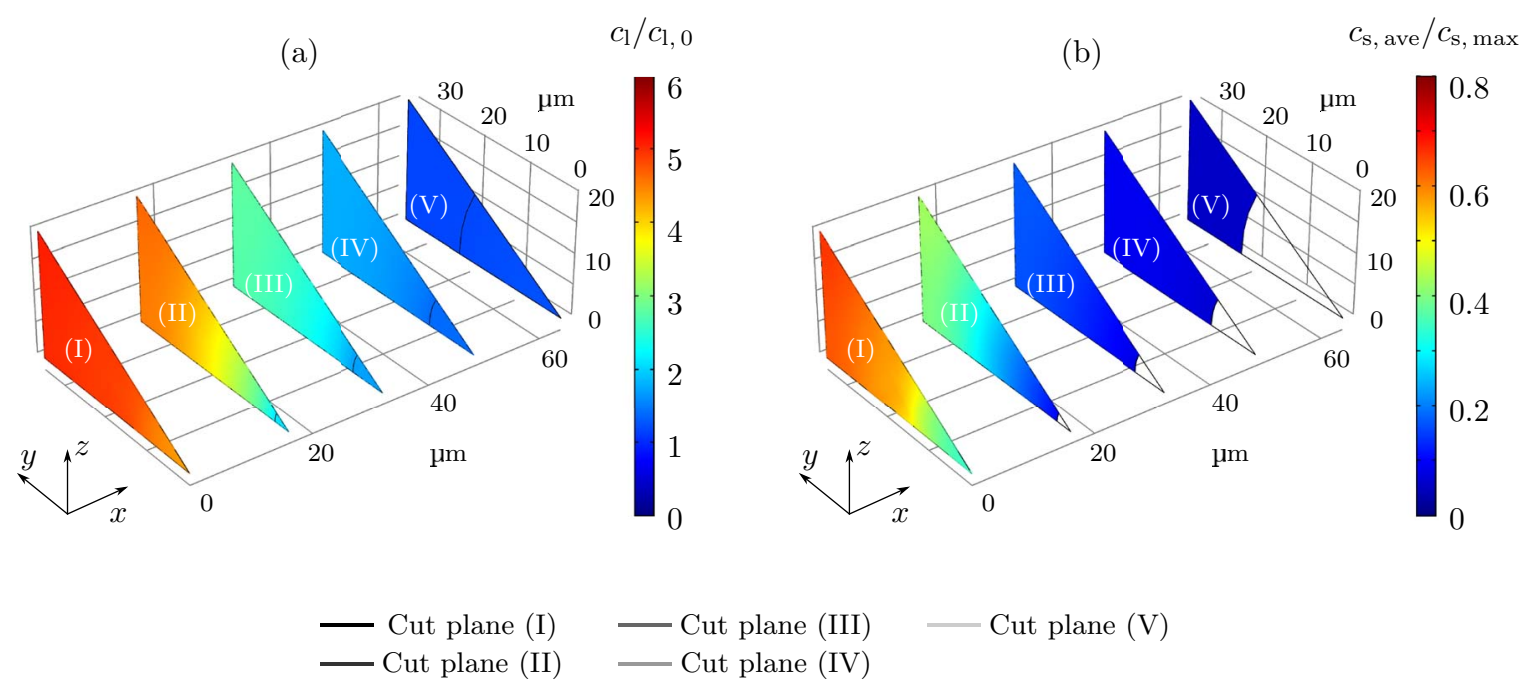

(c)

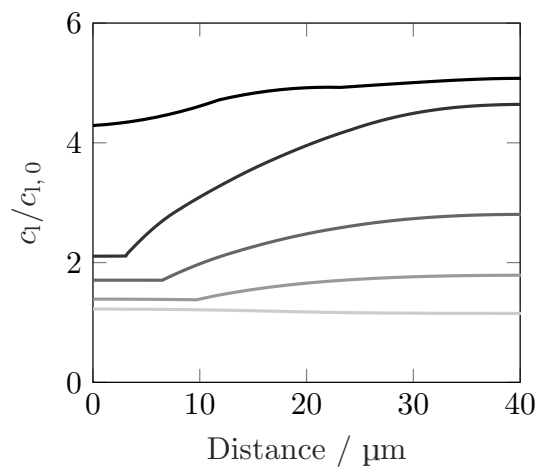

(d)

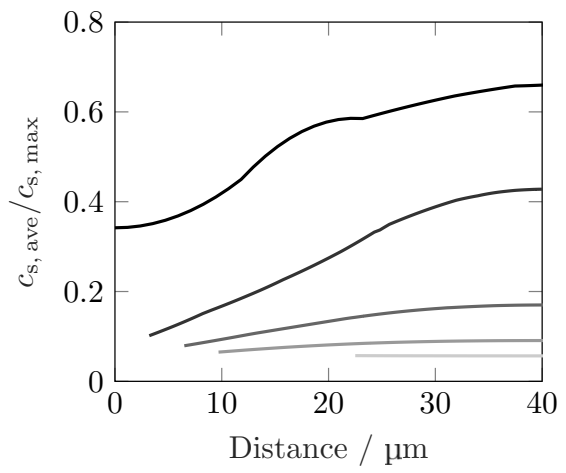

Figure 8. Liquid (a) and solid phase (b) Li-ion concentration on defined cut planes (I), (II), (III), (IV) and (V) (distance in $x$-direction: $0 \mu \mathrm{m}, 16 \mu \mathrm{m}, 32 \mu \mathrm{m}$, $48 \mu \mathrm{m}$ and $64 \mu \mathrm{m}$, respectively) and liquid (c) and solid phase (d) Li-ion concentration along hypotenuse of cut planes at the end of a $3 \mathrm{C}$ discharge step within the structured graphite anode.

increased by a factor of approximately 15 compared to a standard $\mathrm{p} 2 \mathrm{D}$ model (30000 DOF vs. 2000 DOF).

Simulated rate capability tests, which were carried out with the aid of the parametrized structured electrode model, were validated against experimental data showing again excellent agreement in terms of the transient voltage decline during discharge as well as the observed reduced capacity retention with increasing $\mathrm{C}$-rate. It was shown, that for the electrode morphologies and materials considered in this case, the maximum benefit of structuring the graphite electrode was around a discharge rate of $3 \mathrm{C}$. At low discharge rates, there is merely an influence of the structuring process (here up to $1 \mathrm{C}$ ), which then suddenly changes at $2 \mathrm{C}$ rising toward its maximum impact at $3 \mathrm{C}$ of gaining between $10 \%$ and $15 \%$ in capacity compared to cells without structured graphite anodes at $\mathrm{C} / 5$. This corresponds to a relative improvement of capacity retention of $11-24 \%$ at $3 \mathrm{C}$, at which the minimum and maximum capacity retention of the structured cells at $3 \mathrm{C}$ are related to the mean capacity retention of the unstructured cells at $3 \mathrm{C}$. Beyond $3 \mathrm{C}$, the impact of the structuring process declines again, however, at a comparably lower rate. This implies, that there forms a certain C-rate region in which the use of structured electrodes can considerably enhance a cell's rate capability forming an optimum. In other words, structured electrodes do not necessarily come with an overall improvement in rate capability of Li-ion cells at all applied currents as mass transport limitations within the electrolyte are still dominating at large currents despite the locally homogenized distribution in Li-ion concentration (e.g. overall electrolyte depletion in the NMC cathode ${ }^{3}$ ). When looking into the simulated spatial Li-ion concentration in the liquid and the solid phase at the end of discharge, the effect of the structuring process on the rate limitation becomes apparent. At low C-rates (i.e. C/5, C/2 and $1 \mathrm{C}$ or stage (I)), the structuring process has almost no influence on the solid phase concentration in both anode and cathode. Consequently, the amount of discharged capacity is rather limited by an increasing polarization due to ohmic losses and charge transfer kinetics instead of transport limitations in the liquid electrolyte. At higher C-rates (i.e. $2 \mathrm{C}$ and $3 \mathrm{C}$ or stage (II)), the homogenized liquid phase concentration has a more dominant impact on the distribution in liquid and solid phase concentration especially in the graphite anode which results in higher degrees of utilization within both electrodes. When further increasing the discharge rate (i.e. 4C, 5C and 10C or stage (III)), the positive impact of electrode structuring on the homogeneity of liquid phase concentration fades, which then results in a similarly inhomogeneous utilization of the graphite anode. What also becomes apparent is that the level in liquid phase concentration within the cathode generally decreases with increasing C-rate which is based on the ongoing depletion of the electrolyte resulting in increased charge transfer overpotentials. Similarly, the liquid phase concentration within the anode becomes excessively high $\left(>4 \mathrm{moll}^{-1}\right)$, which significantly reduces the inherent transport properties of the electrolyte, resulting in large ohmic and diffusion based overpotentials. This effect cannot be significantly influenced by a structuring of the anode but needs further modifications such as using enhanced electrolytes or including an additional structuring of the cathode.

The results shown in this work imply that not only the anode structuring process can enhance the discharge rate capability of the entire cell in a certain range but also that modeling and simulation 
can help to understand the underlying mechanisms and interactions resulting in this enhancement. By evaluating the through-plane and inplane distribution in Li-ion concentration throughout the electrodes, the ideal hole size, geometry and pattern can be identified in order to maximize the rate capability within a limited operating window. By further considering the costs of the electrode structuring process and also of the excess electrolyte within the holes, a cost-effective rate capability enhancement can be achieved. This can be best explained when considering Fig. 5b, where the peak location, height and width of the curve can be altered by changing the size, the shape and the pattern of the superimposed structure. In order to be able to reliably optimize the structure, inherent transport properties of the applied electrolyte need to be characterized well throughout the entire concentration range occurring during operation before salt precipitation takes place (i.e. beyond $4 \mathrm{moll}^{-1}$ in this case). The same holds true for a thorough characterization of the anisotropic electrode morphology. Further work will focus on this optimization procedure, not only for the graphite anode, but also for the NMC cathode during both discharge and charge operation for various electrode loadings. Furthermore, the model error accompanied with the homogenization of the microstructure will be evaluated and investigated in terms of means of a further model order reduction.

\section{Acknowledgment}

This work was financially supported by the German Federal Ministry of Education and Research (BMBF) under grant number 03XP0081 (ExZellTUM II) and 03XP0027G (MiBZ).

\section{Appendix}

In the experimental section, the open circuit potential measurements of the half cells were described. In Fig. A1, the derived curves are plotted as a function of degree of lithiation.

The developed model is based on the subsequent equations. For a more detailed description, the reader is referred to the work of the Newman group. ${ }^{13,14,16}$ The most relevant model parameters used in this work are listed in Table AI. The mass balance is applied in the porous intercalation electrodes

$$
\varepsilon_{1} \frac{\partial c_{1}}{\partial t}=\nabla\left(D_{1, \text { eff }} \nabla c_{1}-\frac{i_{1} t_{+}}{F}\right)+\frac{3 \varepsilon_{\mathrm{s}}}{r_{\mathrm{p}}} j_{\mathrm{n}}
$$

where $\varepsilon_{1}$ is the porosity or the liquid phase fraction of the electrode domain, $D_{1, \text { eff }}$ the effective diffusivity, $i_{1}$ the ionic current density, $F$ the Faraday constant, $\varepsilon_{\mathrm{s}}$ the solid phase fraction, $r_{\mathrm{p}}$ the particle radius and $j_{\mathrm{n}}$ the pore wall flux. In the separator, there is no charge transfer reaction taking place, hence, the mass balance simplifies to

$$
\varepsilon_{1} \frac{\partial c_{1}}{\partial t}=\nabla\left(D_{1, \text { eff }} \nabla c_{1}-\frac{i_{1} t_{+}}{F}\right)
$$

The ionic current density accounts for the interaction between the different species in the electrolyte which is why the activity dependence is essential

$$
i_{1}=-\kappa_{\mathrm{eff}} \nabla \Phi_{1}+\frac{2 \kappa_{\mathrm{eff}} R T}{F}\left(1+\frac{\partial \ln f_{ \pm}}{\partial \ln c_{1}}\right)\left(1-t_{+}\right) \nabla \ln c_{1}
$$

(a)

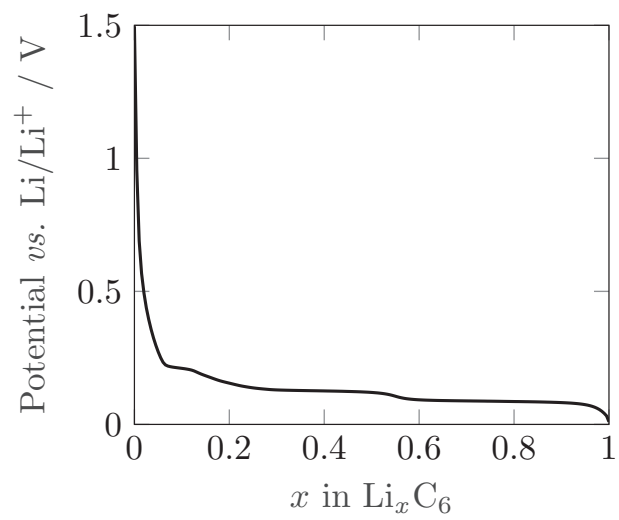

with $\kappa_{\text {eff }}$ being the effective ionic conductivity, $\Phi_{1}$ the potential in the liquid phase and $R$ the ideal gas constant. At high $\mathrm{C}$-rates the Li-ion concentration in the electrolyte can locally become very low due to transport limitations. To prevent the concentration from becoming zero or even negative, which causes instability of the model, a kinetic modification introduced by the Newman group ${ }^{27}$ was implemented. The Butler-Volmer equation, which describes the charge transfer between the solid and the liquid phase on the particle surface is divided by a limitation term with $c_{\text {lim }}=1 \mathrm{~mol} \mathrm{~m}^{-3}$

$$
j_{\mathrm{n}}=\frac{i_{0}}{F} \frac{\exp \left(\frac{\alpha_{\mathrm{a}} F}{R T} \eta\right)-\exp \left(-\frac{\alpha_{\mathrm{c}} F}{R T} \eta\right)}{1+\frac{c_{\lim }}{c_{1}} \exp \left(-\frac{\alpha_{\mathrm{c}} F}{R T} \eta\right)}
$$

$\alpha_{\mathrm{a}}$ and $\alpha_{\mathrm{c}}$ are the anodic and cathodic charge-transfer coefficients. The exchange current density $i_{0}$ is defined as

$$
i_{0}=F k_{\mathrm{c}}^{\alpha_{\mathrm{a}}} k_{\mathrm{a}}^{\alpha_{\mathrm{c}}}\left(c_{\mathrm{s}, \max }-c_{\mathrm{s}}\right)^{\alpha_{\mathrm{a}}} c_{\mathrm{s}}^{\alpha_{\mathrm{c}}}\left(\frac{c_{1}}{c_{1, \text { ref }}}\right)^{\alpha_{\mathrm{a}}}
$$

with $c_{1, \text { ref }}=1 \mathrm{~mol} \mathrm{~m}^{-3} \cdot c_{\mathrm{s}, \max }$ is the maximum Li-ion concentration in the solid phase and $k_{\mathrm{a}}$ and $k_{\mathrm{c}}$ are the anodic and cathodic reaction rates, respectively. The overpotential $\eta$ is defined as a subtraction of the potential of the liquid phase $\Phi_{1}$ and the equilibrium voltage $E_{\text {eq }}$ from the potential of the solid phase $\Phi_{\mathrm{s}}$

$$
\eta=\Phi_{\mathrm{s}}-\Phi_{1}-E_{\mathrm{eq}}
$$

Finally, the following boundary conditions have to be maintained

$$
\begin{aligned}
& \left.\frac{\partial c_{1}}{\partial x}\right|_{x=0 \& x=L}=0 \\
& \left.\frac{\partial \Phi_{1}}{\partial x}\right|_{x=0 \& x=L}=0
\end{aligned}
$$

with $L=l_{\text {neg }}+l_{\text {sep }}+l_{\text {pos }}$.

$$
\left.\frac{\partial \Phi_{\mathrm{s}}}{\partial x}\right|_{x=0 \& x=L}=-\frac{i_{\mathrm{s}}}{\sigma}
$$

with $i_{\mathrm{s}}$ being the electric current density.

$$
\begin{gathered}
\left.\frac{\partial \Phi_{\mathrm{s}}}{\partial x}\right|_{x=l_{\text {neg }} \& x=l_{\text {neg }}+l_{\text {sep }}}=0 \\
\nabla i_{1}=-\nabla i_{\mathrm{s}}
\end{gathered}
$$

$$
\left.\frac{\partial c_{\mathrm{s}}}{\partial r}\right|_{r=0}=0
$$

$$
\begin{gathered}
\frac{\partial c_{\mathrm{s}}}{\partial r}=D_{\mathrm{s}}\left(\frac{\partial^{2} c_{\mathrm{s}}}{\partial r^{2}}+\frac{2}{r} \frac{\partial c_{\mathrm{s}}}{\partial r}\right) \\
-\left.D_{\mathrm{s}} \frac{\partial c_{\mathrm{s}}}{\partial r}\right|_{r=r_{\mathrm{p}}}=j_{\mathrm{n}}
\end{gathered}
$$

In literature, only a few electrolytes used in Li-ion cells have been characterized adequately so that they can be used for the purpose of model parameterization. ${ }^{27-31}$ Necessary characteristics are diffusivity, ionic conductivity and activity dependence of the electrolyte. These characteristics depend on the Li-ion concentration and on the

(b)

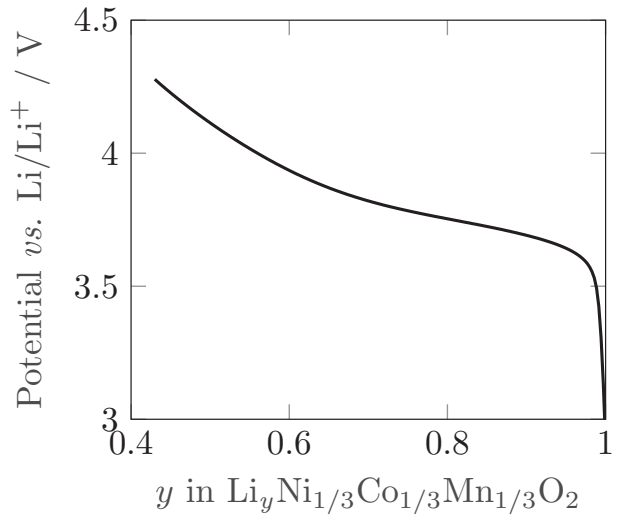

Figure A1. Open circuit potential curves for the graphite anode (a) and the NMC cathode (b) considered in this work. 
Table AI. Model parameters used within this work; superscript $\boldsymbol{m}$ indicates measured values, $e$ indicates estimated values (* value derived from D50 mass-median-diameter from datasheet, ** value derived from weight ratio of electrode composition); numeric values and magnitudes of parameters chosen in this study were referenced to literature where applicable.

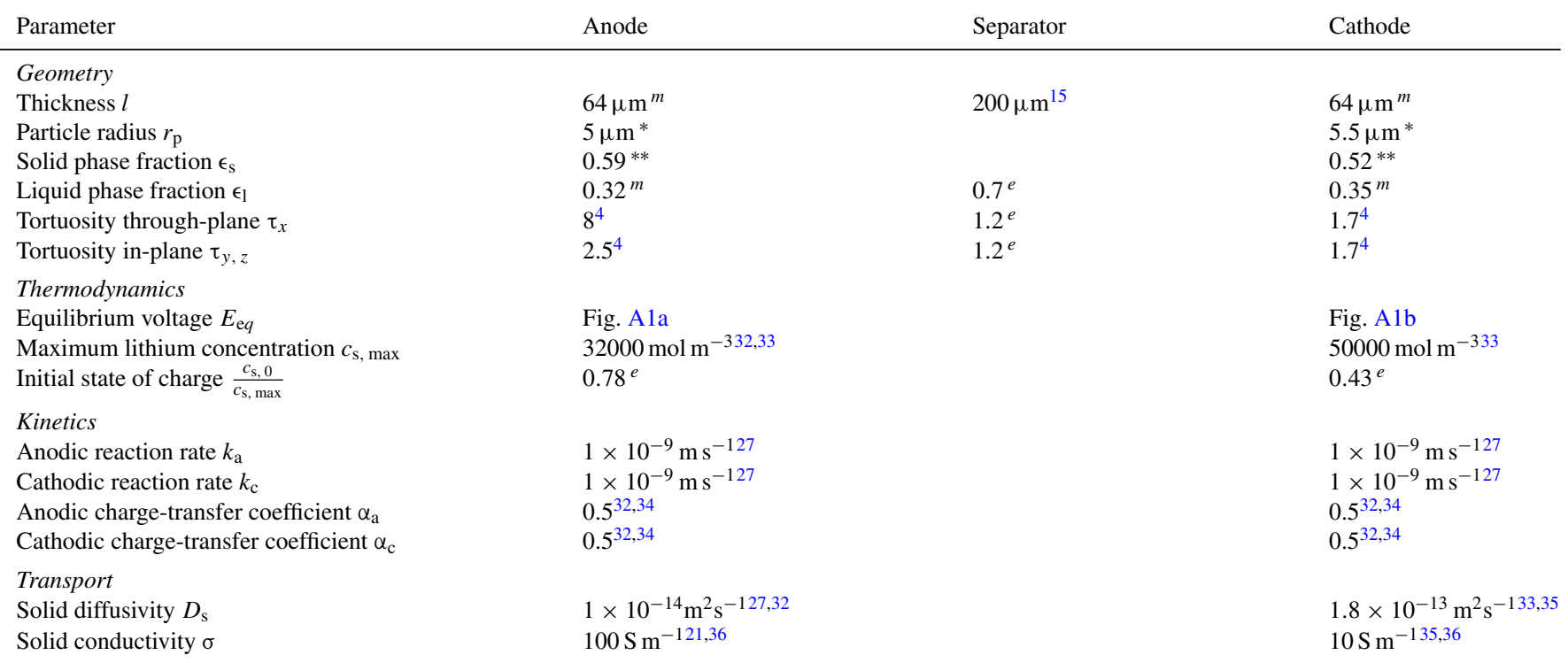

\begin{tabular}{ll}
\hline Parameter & Hole \\
\hline Inner radius $r_{\mathrm{i}}$ & $7.5 \mu \mathrm{m}^{m}$ \\
Outer radius $r_{\mathrm{o}}$ & $22.5 \mu \mathrm{m}^{m}$ \\
Depth $d$ & $0.8 \cdot l_{\text {neg }}{ }^{m}$ \\
Weighting factor $w_{1}$ & 1.1 \\
Weighting factor $w_{2}$ & 0.6 \\
Distance $2 l_{y}$ & $70 \mu \mathrm{m}^{m}$ \\
\hline Parameter & Electrolyte \\
\hline Electrolyte diffusivity $D_{\mathrm{l}}$ & Eq. A15 \\
Electrolyte conductivity $\kappa_{\text {fit }}$ & Eq. A17 \\
Activity dependence $\frac{\partial \ln f_{ \pm}}{\partial \ln c_{1}}$ & Eq. A18 \\
Transport number $t_{+}$ & $0.4^{27}$ \\
\hline Parameter & \\
\hline Temperature $T$ & Global \\
Ohmic contact resistance $R_{\Omega}$ & $293.15 \mathrm{~K}^{m}$ \\
& $1.3 \times 10^{-3} \Omega \mathrm{m}^{2 e}$
\end{tabular}

temperature, which is kept constant in this case. Due to various electrolyte compositions, the resulting curves differ slightly but overall show a similar trend.

The electrolyte diffusion coefficient and the electrolyte ionic conductivity were adopted according to Mao et al. ${ }^{27}$ The corresponding unit for the following characteristic electrolyte functions is $\mathrm{moll}^{-1}$ for the Li-ion concentration $c_{1}$ and $\mathrm{K}$ for the temperature $T$

$$
\begin{gathered}
D_{l}=5.34 \times 10^{-10} \exp \left(-0.65 c_{1}\right) \exp \left(\frac{2000(T-298)}{298 T}\right) f \\
\kappa=\left(0.0911+1.9101 c_{1}-1.052 c_{1}^{2}+0.1554 c_{1}^{3}\right) \exp \left(\frac{1690(T-298)}{298 T}\right)
\end{gathered}
$$

The electrolyte diffusion coefficient was slightly reduced by multiplying a factor $f=0.85$. Mao et al. ${ }^{27}$ used a polynomial fitting function for the ionic conductivity that is only valid in a certain concentration range. For concentrations above $3 \mathrm{moll}^{-1}$, the conductivity starts to increase again due to the considered cubic fitting function. As larger Li-ion concentrations were observed in this work, the following fit was used, which is based on Eq. A16 with a constant temperature $T=293.15 \mathrm{~K}$

$$
\kappa_{\text {fit }}=2.034\left(\frac{c_{1}}{2.512}\right)^{0.55} \exp \left(-\left(\frac{c_{1}}{2.512}\right)^{1.55}\right)
$$

The effective diffusivity and ionic conductivity can be determined using the correction presented in Eqs. 4 and 5. The electrolyte activity dependence was taken from Valøen and Reimers $^{28}$ as it was neglected by Mao et al. ${ }^{27}$

$$
\frac{\partial \ln f_{ \pm}}{\partial \ln c_{1}}=\frac{0.601-0.24 c_{1}^{0.5}+0.982 c_{1}^{1.5}(1-0.0052(T-294))}{1-t_{+}}-1
$$

The equation contains a dependence of the transport number $t_{+}$, which was set constant, see Table AI.

\section{ORCID}

Jan B. Habedank (D) http://orcid.org/0000-0003-2057-7037

Ludwig Kraft (10) http://orcid.org/0000-0003-4324-426X

Alexander Rheinfeld (D) http://orcid.org/0000-0003-0995-7266

\section{References}

1. M. Singh, J. Kaiser, and H. Hahn, "Thick Electrodes for High Energy Lithium Ion Batteries," Journal of the Electrochemical Society, 162, A1196 (2015).

2. A. Nyman, T. G. Zavalis, R. Elger, M. Behm, and G. Lindbergh, "Analysis of the Polarization in a Li-Ion Battery Cell by Numerical Simulations," Journal of The Electrochemical Society, 157, A1236 (2010).

3. K. G. Gallagher, S. E. Trask, C. Bauer, T. Woehrle, S. F. Lux, M. Tschech, P. Lamp, B. J. Polzin, S. Ha, B. Long, Q. Wu, W. Lu, D. W. Dees, and A. N. Jansen, "Optimizing Areal Capacities through Understanding the Limitations of Lithium-Ion Electrodes," Journal of The Electrochemical Society, 163, A138 (2015).

4. M. Ebner, D.-W. Chung, R. E. García, and V. Wood, "Tortuosity Anisotropy in Lithium-Ion Battery Electrodes," Advanced Energy Materials, 4, 1 (2014).

5. M. Osiak, H. Geaney, E. Armstrong, and C. O'Dwyer, "Structuring materials for lithium-ion batteries: Advancements in nanomaterial structure, composition, and defined assembly on cell performance," Journal of Materials Chemistry, A 2, 9433 (2014). 
6. C. L. Cobb and M. Blanco, "Modeling mass and density distribution effects on the performance of co-extruded electrodes for high energy density lithium-ion batteries," Journal of Power Sources, 249, 357 (2014).

7. C.-J. Bae, C. K. Erdonmez, J. W. Halloran, and Y.-M. Chiang, "Design of battery electrodes with dual-scale porosity to minimize tortuosity and maximize performance," Advanced materials, 25, 1254 (2013).

8. S. Ferrari, M. Loveridge, S. D. Beattie, M. Jahn, R. J. Dashwood, and R. Bhagat, "Latest advances in the manufacturing of 3D rechargeable lithium microbatteries," Journal of Power Sources, 286, 25 (2015).

9. J. Pröll, H. Kim, A. Piqué, H. J. Seifert, and W. Pfleging, "Laser-printing and femtosecond-laser structuring of $\mathrm{LiMn}_{2} \mathrm{O}_{4}$ composite cathodes for Li-ion microbatteries," Journal of Power Sources, 255, 116 (2014).

10. J. B. Habedank, J. Endres, P. Schmitz, H. P. Huber, and M. F. Zaeh, "Femtosecond laser structuring of graphite anodes for improved lithium-ion batteries: Ablation characteristics and process design," Journal of Laser Applications (2018) (accepted for publication) 2018 .

11. C. L. Cobb and S. E. Solberg, "Communication-Analysis of Thick Co-Extruded Cathodes for Higher-Energy-and-Power Lithium-Ion Batteries," Journal of The Electrochemical Society, 164, A1339 (2017).

12. V. P. Nemani, S. J. Harris, K. C. Smith, and Design of Bi-Tortuous, "Anisotropic Graphite Anodes for Fast Ion-Transport in Li-Ion Batteries," Journal of The Electrochemical Society, 162, A1415 (2015).

13. J. Newman and K. E. Thomas-Alyea, Electrochemical Systems, 3rd ed.; John Wiley \& Sons, Inc.: Hoboken, New Jersey, 2004.

14. M. Doyle, T. F. Fuller, and J. Newman, "Modeling of Galvanostatic Charge and Discharge of the Lithium/Polymer/Insertion Cell," Journal of the Electrochemical Society, 140, 1526 (1993).

15. J. Landesfeind, D. Pritzl, and H. A. Gasteiger, "An Analysis Protocol for ThreeElectrode Li-Ion Battery Impedance Spectra: Part I. Analysis of a High-Voltage Positive Electrode," Journal of the Electrochemical Society, 164, A1773 (2017).

16. T. F. Fuller, M. Doyle, and J. Newman, "Simulation and Optimization of the Dual Lithium Ion Insertion Cell," Journal of the Electrochemical Society, 141, 1 (1994).

17. F. M. Kindermann, P. J. Osswald, G. Ehlert, J. Schuster, A. Rheinfeld, and A. Jossen, "Reducing Inhomogeneous Current Density Distribution in Graphite Electrodes by Design Variation," Journal of The Electrochemical Society, 164, E3105 (2017).

18. F. M. Kindermann, P. J. Osswald, S. Klink, G. Ehlert, J. Schuster, A. Noel, S. V. Erhard, W. Schuhmann, and A. Jossen, “, Measurements of lithium-ion concentration equilibration processes inside graphite electrodes," Journal of Power Sources, 342, 638 (2017).

19. S. V. Erhard, P. J. Osswald, J. Wilhelm, H. E. Hoster, and A. Jossen, "Simulation and Measurement of Local Potentials of Modified Commercial Cylindrical Cells: II: Multi-Dimensional Modeling and Validation," Journal of The Electrochemical Society, 162, A2707 (2015).

20. S. V. Erhard, et al. Simulation and Measurement of the Current Density Distribution in Lithium-Ion Batteries by a Multi-Tab Cell Approach," Journal of The Electrochemical Society, 164, A6324 (2017).
21. M. Doyle and J. Newman, "Comparison of Modeling Predictions with Experimental Data from Plastic Lithium Ion Cells," Journal of the Electrochemical Society, 143, 1890 (1996)

22. K. K. Patel, J. M. Paulsen, and J. Desilvestro, "Numerical simulation of porous networks in relation to battery electrodes and separators," Journal of Power Sources, 122, 144 (2003).

23. I. V. Thorat, D. E. Stephenson, N. A. Zacharias, K. Zaghib, J. N. Harb, and D. R. Wheeler, "Quantifying tortuosity in porous Li-ion battery materials," Journal of Power Sources, 188, 592 (2009).

24. J. Landesfeind, J. Hattendorff, A. Ehrl, W. A. Wall, and H. A. Gasteiger, "Tortuosity Determination of Battery Electrodes and Separators by Impedance Spectroscopy," Journal of The Electrochemical Society, 163, A1373 (2016).

25. R. B. MacMullin and G. A. Muccini, "Characteristics of porous beds and structures," AIChE Journal, 2, 393 (1956).

26. M. J. Martínez, S. Shimpalee, and J. W. van Zee, "Measurement of MacMullin Numbers for PEMFC Gas-Diffusion Media," Journal of the Electrochemical Society, 156 B80 (2009).

27. J. Mao, W. Tiedemann, and J. Newman, "Simulation of temperature rise in Li-ion cells at very high currents," Journal of Power Sources, 271, 444 (2014)

28. L. O. Valøen and J. N. Reimers, "Transport Properties of $\mathrm{LiPF}_{6}-\mathrm{Based} \mathrm{Li-}$ Ion Battery Electrolytes," Journal of the Electrochemical Society, 152, A882 (2005).

29. A. Nyman, M. Behm, and G. Lindbergh, "Electrochemical characterisation and modeling of the mass transport phenomena in $\mathrm{LiPF}_{6}-\mathrm{EC}-\mathrm{EMC}$ electrolyte," Electrochimica Acta, 53, 6356 (2008).

30. M. Guo and R. E. White, "A distributed thermal model for a Li-ion electrode plate pair," Journal of Power Sources, 221, 334 (2013).

31. H. Lundgren, M. Behm, and G. Lindbergh, "Electrochemical Characterization and Temperature Dependency of Mass-Transport Properties of LiPF 6 in EC:DEC, "Journal of the Electrochemical Society, 162, A413 (2014).

32. P. Ramadass, B. Haran, P. M. Gomadam, R. White, and B. N. Popov, "Developmen of First Principles Capacity Fade Model for Li-Ion Cells," Journal of The Electrochemical Society, 151, A196 (2004).

33. S. Tippmann, D. Walper, L. Balboa, B. Spier, and W. G. Bessler, "Low-temperature charging of lithium-ion cells part I: Electrochemical modeling and experimental investigation of degradation behavior," Journal of Power Sources, 252, 305 (2014).

34. M. Doyle and Y. Fuentes, "Computer Simulations of a Lithium-Ion Polymer Battery and Implications for Higher Capacity Next-Generation Battery Designs," Journal of The Electrochemical Society, 150, A706 (2003).

35. M. Park, X. Zhang, M. Chung, G. B. Less, and A. M. Sastry, "A review of conduction phenomena in Li-ion batteries," Journal of Power Sources, 195, 7904 (2010).

36. K. Smith and C.-Y. Wang, "Power and thermal characterization of a lithium-ion battery pack for hybrid-electric vehicles," Journal of Power Sources, 160, 662 (2006). 